\title{
USO DAS REDES SOCIAIS NA EDUCAÇÃO PROFISSIONAL E TECNOLÓGICA
}

\author{
Use of social networks in professional and technological education
}

Uso de las redes sociales en la educación profesional y tecnológica

RESUMO A página AMBIÉTICA possui cinco anos, criada no Facebook e administrada pelos estudantes do $5^{\circ}$. semestre de Tecnologia em Gestão Ambiental do Instituto Federal de Educação, Ciência e Tecnologia de Mato Grosso campus Cuiabá, Bela Vista, como atividade da disciplina de Ética Ambiental - CQA 316. A página objetiva a interação entre os conteúdos de educação e ética ambiental, com predomínio da autonomia e criatividade dos estudantes para com as postagens. Por meio do artigo, relacionam-se os resultados pedagógicos dessas atividades com alguns referenciais teóricos na educação como: o pensar complexo de Matthew Lipman e Antoni Zabala, a autonomia de Paulo Freire, pensamento narracional de Hannah Arendt e os conceitos das NTICs, como: cibercultura de Pierry Lèvy, Sociedade em Rede de Manuel Castells. A pesquisa utilizou a documentação direta, pesquisa de campo e a aplicação de questionários. Considera-se que os objetivos propostos pela AMBIÉTICA foram atingidos, uma vez que a temática ambiental e outras de cunho social foram amplamente debatidas, na perspectiva de reações ulteriores que, para além dos limites da sala de aula, produziram autonomia e um pensar complexo.

Palavras-chave: Novas tecnologias educacionais. Redes SoCIAIS. ENSINO. EDUCAÇÃO AMBIENTAL. ÉTICA AMBIENTAL.

Abstract The AMBIÉTICA page is five years old, created on Facebook and administered by the students of the 5 th semester of Environmental Management Technology of the Federal Institute of Education, Science and Technology of Mato Grosso, Cuiabá campus, Bela Vista, as an activity of the discipline of Environmental Ethics - CQA 316. The page aims at the interaction between education content and environmental ethics, with a predominance of student's autonomy and creativity towards posts. Through the article the pedagogical results of these activities are related to some theoretical references in education such as the complex thinking of Matthew Lipman and Antoni Zabala, Paulo

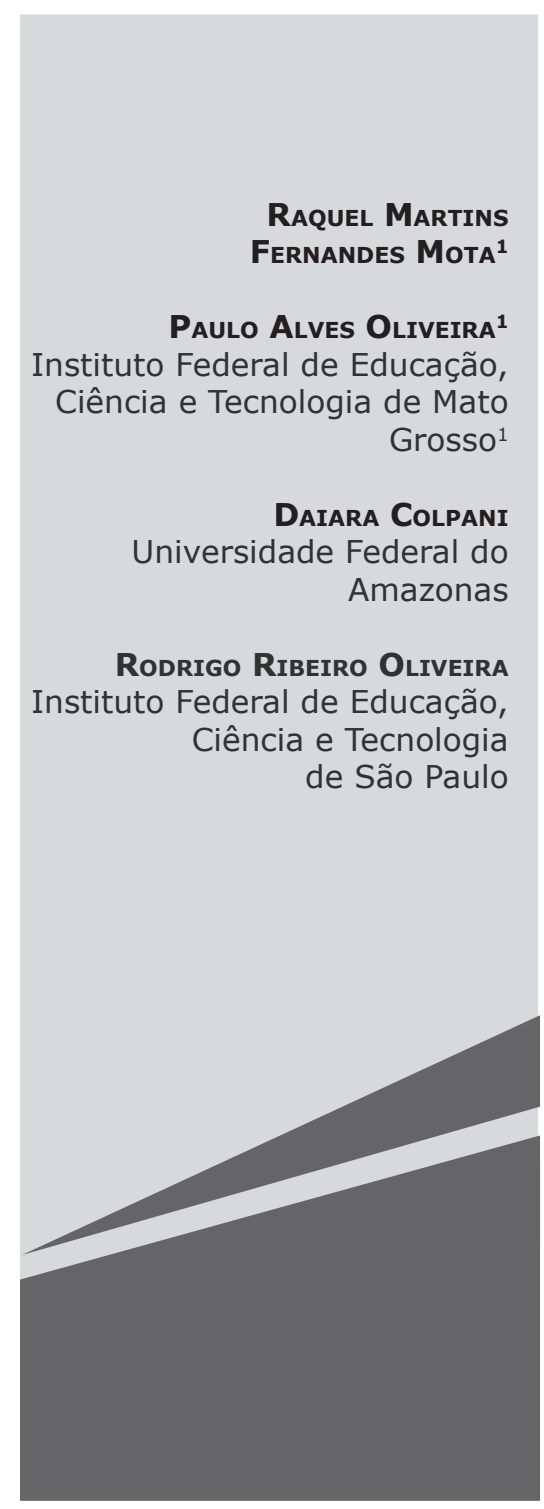


Freireautonomy, Hannah Arendt's narrative thinking and the concepts of NICTs such as: cyberculture by Pierry Lèvy, Network Society of Manuel Castells. The research utilized direct documentation, field research and the application of questionnaires. It is considered that the objectives proposed by AMBIÉTICA were reached, since the environmental and other social issues were widely debated, in the perspective of later reactions that, beyond the limits of the classroom, produced autonomy and a complex thinking.

KEYWORDS: NEW EDUCATIONAL TECHNOLOGIES. SOCIAL NETWORKS. TEACHING. ENVIRONMENTAL EDUCATION. ENVIRONMENTAL ETHICS.

RESUMEN La página AMBIÉTICA tiene cinco años, creada en Facebook y administrada por los estudiantes del $5^{\circ}$. semestre de Tecnología en Gestión Ambiental del Instituto Federal de Educación, Ciencia y Tecnología de Mato Grosso campus Cuiabá, Bela Vista, como actividad de la disciplina de Ética Ambiental - CQA 316. La página objetiva la interacción entre los contenidos de educación y ética ambiental, con predominio de la autonomía y creatividad de los estudiantes para con las posturas. A través del artículo se relacionan los resultados pedagógicos de estas actividades con algunos referenciales teóricos en la educación como: el pensamiento complejo de Matthew Lipman y Antoni Zabala, la autonomía de Paulo Freire, pensamiento narracional de Hannah Arendt y los conceptos de las NTICs, tales como: cibercultura de Pierry Lèvy, Sociedad en Red de Manuel Castells. La investigación se utilizó de la documentación directa, investigación de campo y la aplicación de cuestionarios. Se considera que los objetivos propuestos por la AMBIÉTICA fueron alcanzados, una vez que la temática ambiental y otras de cuño social, fueron ampliamente debatidas, en la perspectiva de reacciones ulteriores que, más allá de los límites del aula, produjeron autonomía y un pensamiento complejo.

Palabras Clave: NueVAS tecnologías educativas. Redes SOCIALES. EDUCACIÓN. EDUCACIÓN AMBIENTAL. ÉTICA AMBIENTAL.

\section{INTRODUÇÃo}

Os Institutos Federais (IF's) são instituições de Educação Superior, básica e profissional, pluricurriculares e multicampi, especializados na oferta de educação profissional e tecnológica nas diferentes modalidades de ensino, com base na conjugação de conhecimentos técnicos e tecnológicos com as suas práticas pedagógicas (BRASIL, 2008). O formato característico da fundação dos mesmos evidencia uma perspectiva de formação profissional e tecnológica com o objetivo de favorecer a "consolidação e fortalecimento dos arranjos produtivos, sociais e culturais locais" (BRASIL, 2008, p. 2), que remetem a um ensino não meramente tecnicista, como afirmam Afonso e Gonzales (2016, p. 719): 
A Educação Profissional e Tecnológica (EPT) é historicamente influenciada por diferentes concepções de formação, dentre elas a que defende uma formação voltada para atender aos anseios dos arranjos produtivos, ao modelo de desenvolvimento econômico, implicando em uma formação tecnicista com foco no mercado de trabalho; ou a que almeja uma formação profissional humanista, unitária ou na perspectiva da politécnica, com foco na formação integral do trabalhador.

Nesse sentido, disciplinas de formação humanística coadunam nesse processo, e no intuito de fomentar o viés tecnológico junto ao social é que se propôs o uso de novas tecnologias de informação e comunicação (NTICS), bem como, redes sociais, como o Facebook, em atividades didático-pedagógicas no âmbito do ensino-pesquisa-extensão de maneira indissociável.

Nesse contexto, observou-se que a página AMBIÉTICA, na rede social Facebook, atualmente é a maior rede social do mundo, para além de seus 2,27 bilhões de usuários ativos mensais, no mundo, com 130 milhões no Brasil. Os usuários ativos são aqueles que efetuaram login no Facebook durante os últimos 30 dias (STATISTA, 2018a; STATISTA, 2018b).

Fez-se uma análise da repercussão da rede social, por meio dos comentários, compartilhamentos, curtidas e publicações que foram realizados na linha do tempo AMBIÉTICA, por intermédio dos conceitos revisados da literatura educacional: pensar complexo de Matthew Lipman e Antoni Zabala, autonomia de Paulo Freire, pensamento narracional de Hannah Arendte, e os conceitos relativos às novas tecnologias de informação e de comunicação (NTICs), como: cibercultura de Pierry Lèvy e Sociedade em Rede de Manuel Castells, além de avaliar as três edições do CURTABLV (Festival de Vídeo Curta Metragem Ambiental), 2013, 2014 e 2015, a partir da sua repercussão e participação da comunidade escolar.
$\mathrm{O}$ artigo analisa e busca compreender a contribuição da AMBIÉTICA, em redes sociais, para a formação educacional do estudante $\mathrm{e}$ para a efetivação do tripé ensino-pesquisa-extensão.

\section{ContextualizaÇão histórico- CONCEITUAL}

A linguagem digital é uma nova forma de comunicação social advinda das novas tecnologias, que foram desenvolvidas ao longo dos últimos anos, as quais influenciam a vida social e se relacionam com os diversos campos do saber humano. Conceitos como Sociedade em Rede (CASTELLS, 2013), Galáxia da internet (CASTELLS, 2003), Cibercultura (LÉVY, 1999b), Virtualização (LÉVY, 1999C), e Inteligência Coletiva (LÉVY, 1998), configuram a linguagem digital. Essas novas formas de comunicação têm como ferramentas as novas interfaces das tecnologias da informação desenvolvidas a partir da década 1970, com a criação do computador e a inserção da internet desde a década de 1990, as quais influenciaram a vida social e se ramificam com os diversos campos do saber humano.

Castells (2013, p. 39) afirma que se tem uma sociedade em rede vivendo a Era da Informação, o que pode alterar profundamente a cultura, o modo de produção e os fluxos da informação. E, ainda, que devido à penetrabilidade em todas essas esferas da vida humana, a revolução da tecnologia da informação será o ponto inicial para analisar a complexidade de uma nova economia, sociedade e cultura em formação.

Lévy (1995, p. 4) explica que novas formas de pensar e conviver estão sendo elaboradas no mundo das telecomunicações e da informática. As relações entre os homens, o trabalho, a sua própria inteligência, estão dependendo de dispositivos informacionais de todos os tipos. A cada dia que passa, a escrita, a leitura, a visão, a audição, a criação e a aprendizagem são capturadas pela informática, que avança a cada momento. 
Esses avanços, Lévy (1999b, p. 17) denomina de cibercultura e os entende como um conjunto de técnicas, materiais ou intelectuais, de práticas, de atitudes, de modos de pensamento e de valores, que foram desenvolvidos com o crescimento do ciberespaço. Sobre o ciberespaço, para o autor, é a própria rede se configurando também como um novo meio de comunicação que surge da interconexão mundial dos computadores. Especificando não apenas a infraestrutura material da comunicação digital, mas o universo de informações que a mesma abriga, como os seres humanos que navegam e alimentam esse universo.

Para Lévy (1999b, p. 46), a virtualidade constitui um traço distintivo da nova face da informação, uma vez que a digitalização é o fundamento técnico da virtualidade. Sobre o projeto de Inteligência Coletiva, Lévy (1998) explica que supõe um abandono da perspectiva de poder, uma vez que procura abrir o vazio central, o poço da clareza, que permite o jogo com a alteridade, a quimerização e a complexidade labiríntica.

Castells (2003, p. 7) explica que a internet passou a ser a sustentação tecnológica para as organizações na Era da Informação: a rede é como um conjunto de nós interconectados. A formação das redes envolve práticas humanas antigas, porém, as redes ganharam vida nova apenas neste tempo, constituindo-se em redes de informação intensificadas pela internet.

A industrialização iniciou o homem na era dos maquinários. Essa inserção, passagem da modernidade à contemporaneidade, impôs os novos modos de viver a vida, trazendo novas necessidades de comunicações e da influência das redes sociais nas cotidianidades das pessoas, ou seja, as "novas maneiras de pensar e de conviver estão sendo elaboradas no mundo das telecomunicações e da informática" (LÉVY, 1995, p. 4).

Cada vez mais as pessoas se apresentam conectadas nas redes informáticas e dependentes das mesmas, seja para comunicar, trabalhar e/ou como forma de entretenimento. No âmbito educacional, as novas tecnologias são altamente questionadas quanto aos seus prós e contras. Considera-se de extrema importância que a escola seja, enquanto unidade educadora, adaptada aos novos conceitos tecnológicos para, assim, atender de modo satisfatório às exigências da modernidade. Entretanto, ocorre com frequência:

(...) excesso nas mídias, onde as performances tecnológicas e o consumo de informação submergem, "anestesiam" a capacidade de análise dessa informação e de reflexão tanto individual quanto social. Saturação e superabundância ameaçam o navegador da Internet que, como certas pesquisas mostram, não tira partido das riquezas de informação pertinente, não estando formado para ir diretamente ao essencial (MARCHESSOU, 1997, p. 15).

Portanto, é papel do professor atuar, não apenas como transmissor de conhecimentos, mas também como mediador participativo, sabendo ensinar a selecionar os instrumentos, canais e documentos necessários de acordo com os aspectos pedagógicos.

O computador e tantas outras novas tecnologias, anteriormente, eram usados apenas como aparatos de estudos e pesquisas conduzidas por especialistas. Com o desenvolvimento das ferramentas tecnológicas, principalmente as promovidas com o advento da internet, começam a surgir na sociedade novas formas de comunicação e organização das atividades humanas. Entre estas se destacam as redes sociais virtuais, que são um importante instrumento de socialização universal, possibilitando as inter-relações pessoais e a troca de informações entre pessoas que distam milhares de quilômetros em alguns instantes.

A página AMBIÉTICA foi criada no Facebook pelos estudantes do $5^{\circ}$. semestre do Curso Superior em Tecnologia em Gestão Ambiental do Instituto Federal de Educação, Ciência e Tecnologia de Mato Grosso, campus Cuiabá Bela Vista, e a sua fundação ocorreu 
em 15 de outubro de 2012, em atividade da disciplina de Ética Ambiental, em que educador e estudantes propuseram um meio de compartilhar conhecimentos e gerar conteúdos procedimentais e atitudinais da Ética Ambiental. A princípio sugeriram a criação de um blog, depois, com o crescimento do Facebook, este foi escolhido como plataforma de conhecimento e interação social. O nome Ambiética foi criado pelos próprios estudantes, em uma junção de "ambi" de ambiente e ética, em alusão à própria disciplina.

A metodologia didática utilizada foi a comunidade de investigação, que possui atividades de metodologia de cunho cooperativo (SHARP; SPLITTER, 1998). A comunidade de investigação cria, enquanto prática pedagógica, um ambiente de uma construção ativa, criteriosa, participativa e autocorretiva do conhecimento, por meio de temas/problemas filosóficos, partindo da realidade circundante e permite propiciar a construção de novos significados em um encontro efetivo com conceitos e conteúdos, novos e diversos em uma troca de saberes e descoberta de valores, que resulte em construção cultural.

Por meio da metodologia da comunidade de investigação, o educador favorece um ambiente de investigação sobre temáticas relativas ao conteúdo programático da disciplina e a partir das pesquisas e debates, as produções e/ou pesquisas dos estudantes são compartilhadas na página, e como se trata de um recurso também visual, os estudantes são incentivados a relacionar a ética ambiental com a educação ambiental, no sentido de formação de opinião. Ao mesmo tempo, os estudantes aprendem a usar recursos diversos nas postagens: fotos, músicas, filmes, reportagens, artigos produzidos, entre outros. As postagens são o resultado de atividades de ensino e de pesquisa desenvolvidas durante o semestre. Os conteúdos compartilhados variam entre assuntos ambientais, como: poluição, aquecimento global, extinção de animais, entre outros, até assuntos reflexivos acerca da fome mundial, preconceito racial etc. Os conteúdos postados, muitas vezes, se inter-relacionam com dados geográficos, estatísticos, diferentes estruturas e jogos de linguagem, humor, frases filosóficas, ou seja, incentivam a interdisciplinaridade de assuntos já discutidos em ambiente escolar, trazendo-os às redes sociais.

Desde sua fundação, a página da AMBIÉTICA é um espaço virtual que serve como meio de exposição da temática ambiental, além de, anualmente, ser palco para o CURTABLV. Os vídeos do mesmo ficam expostos na AMBIÉTICA (durante o período estipulado pelo regulamento, que varia entre sete a quinze dias), em que o vídeo com maior número de "curtidas" é vencedor na categoria júri popular, possuindo também uma premiação da categoria do júri técnico (tendo como critérios de avaliação a abordagem do tema, a criatividade e o conjunto da produção em nível técnico).

\section{Pensamento autônomo na aldeia GLOBAL}

Seguem alguns conceitos-chave e possíveis autores de referência para a proposta de uma educação para a cidadania planetária, em educação profissional e tecnológica, como: pensar complexo, a partir do referencial de Matthew Lipman e Antoni Zabala; autonomia, de Paulo Freire, em Pedagogia da Autonomia; e pensamento narracional, de Hannah Arendt, em A Vida do Espírito para observar a página AMBIÉTICA, por intermédio dos três conceitos em questão. Faz-se necessário avaliar, a partir de critérios pedagógicos, a fim de esclarecimentos, visto que a introdução de novas tecnologias educacionais no meio escolar, com frequência, encara desafios e polêmicas quanto à sua eficiência e eficácia na relação ensino/aprendizagem.

Para Lipman: "O pensar é o processo de descobrir ou fazer associações e disjunções" (LIPMAN, 1995, p. 33), produzindo significados. É preciso um pensar "conceitualmente rico, coerentemente organizado e persistentemente investigativo" (LIPMAN, 1995, p. 37), o pensar complexo. No artigo Caring as 
Thinking, Lipman acrescenta a excelência do pensamento proposto, em O Pensar na Educação, a dimensão afetiva e de sensibilidade, em que caring thinking foi traduzido no Brasil por pensar cuidadoso. No fragmento, a seguir, se percebe, em resumo, as características do pensar complexo:

Quando pensamos criticamente, estamos aplicando ao nosso pensar regras, critérios, normas, razões e prescrições que são racionais e adequadas para este fim. Quando pensamos criativamente, estamos inventando caminhos para expressar a nós mesmos ou o mundo ao nosso redor; estamos tentando ultrapassar os caminhos que pensamos no passado; estamos imaginando detalhes de mundos possíveis e propondo inovações não precedidas. Quando pensamos cuidadosamente, somos atenciosos com o que achamos importante, com o que temos sentimentos afetivos, com aquilo que nos exige, requer ou necessita para pensar sobre ele (LIPMAN, 1995, p. 1-13).

Esse pensar é alcançado em um ambiente em que o educador e o educando possuam como competência, em sua práxis, a autonomia do pensar e agir (FREIRE, 1996). Freire (2001, p. 13) afirma: “Aprender e ensinar fazem parte da existência humana, histórica e social, como dela fazem parte a criação, a invenção e os sentimentos". O diálogo e a criação rompem a passividade, permitindo aos participantes do processo de aprendizagem interferir, significativamente, em seu meio social (FREIRE, 1996). A curiosidade, para Freire (1996), impulsiona a busca por esclarecimentos, em uma construção histórica que por meio do diálogo permite compreender o outro. Para Freire (1987, p. 29): "o educador já não é o que apenas educa, mas o que, enquanto educa, é educado, em diálogo com o educando que, ao ser educado, também educa". A educação permite ao homem, enquanto fonte de conhecimento, intervir na realidade e mudar a história, a política, o mundo, em um processo de construção autônoma. A pessoa pode sair de uma condição subjugada e se tornar um agente modificador da realidade.

Para Hannah Arendt, essa práxis é possível por meio da criação que se encontra dentro da vita activa que envolveria não apenas a dimensão pública, mas o labor (atividade biológica), a ação e o trabalho e produção (do artificial).

As coisas e os homens constituem o ambiente de cada uma das atividades humanas, que não teriam sentido se tal localização; e, no entanto, este ambiente, o mundo ao qual viemos, não existiria sem a atividade humana que o produziu, como no caso de coisas fabricadas; que dele cuida, como no caso das terras de cultivo; ou que o estabeleceu através da organização, como no caso do campo político (ARENDT, 2001, p. 31).

Quem cria expressa, em um pensamento narracional, que não reduz o complexo ao conceito, mas reconstitui os significados pela imaginação. Já a percepção difere da intuição e expressão, visto que a primeira é um juízo de existência sobre o belo (Arte), mas não é suficiente para a produção artística (AGUIAR. In: BIGNOTTO, 2003, p. 218).

Segundo Arendt (2001), o pensamento narracional produz a reconciliação efetiva dos homens com as suas experiências, em uma criticidade não abstrata e um desvencilhar da passividade, estimulando um pensamento autônomo (IDEM, p. 224). Nessa perspectiva, Lipman, Freire e Arendt se encontram em dimensões epistemológicas, do primeiro se encontram com as dimensões política e estética dos outros autores respectivamente. 


\section{Metodologia}

A pesquisa se constituiu de três etapas: 1) Pesquisa Bibliográfica; 2) Pesquisa Documental e 3) Pesquisa de Campo. Na pesquisa bibliográfica, realizou-se a leitura de arquivos e livros sobre os temas predominantes no presente artigo, como: redes sociais, ética e educação ambiental. E, na pesquisa documental, foi feita a avaliação de dados qualitativos e quantitativos da página AMBIÉTICA do Facebook. Os dados qualitativos analisados consistem nos conteúdos compartilhados, comentários realizados e sua respectiva relevância ancorada nos conceitos: pensar complexo, autonomia e pensamento narracional. Já os dados quantitativos considerados no número de "curtidas", comentários e compartilhamentos de postagens efetuados na AMBIÉTI$C A$, assim como, no número de pessoas que "curtiram" a AMBIÉTICA, no período de 15 de outubro de 2012 até o dia 6 de abril de 2016.

A pesquisa de campo consistiu na aplicação de questionários com questões relacionadas à página $\mathrm{AMBIÉTICA}$ do Facebook e ao CURTABLV. Foram aplicados dois questionários: $A$ - elaborado para estudantes administradores da página AMBIÉTICA; $B$ - elaborado para estudantes participantes do CURTABLV. Ambos foram constituídos por onze questões e estas foram ancoradas nos conceitos do pensar complexo de Matthew Lipman e Antoni Zabala, autonomia de Paulo Freire, e pensamento narracional, de Hannah Arendt. Cada questionário consistiu em dez questões objetivas, com cinco alternativas cada e uma questão aberta.

As questões estão disponíveis a seguir com suas respectivas palavras-chave em negrito.

\section{Questionário A:}

1. Após conhecer, interagir e publicar na página AMBIÉTICA, responda, fundamentado em sua experiência: a) Você desenvolveu maior criticidade sobre determinado tema? b) Você teve novas ideias/desenvolveu sua criatividade? c) Pesquisou e elaborou, por si mesmo, suas postagens? d) Mudou algo no seu modo de agir e/ou pensar sobre o meio ambiente? e) Você considera que essas atividades tenham contribuído para a construção de um conhecimento significativo? f) Considera ser importante atividade como essa na ética ambiental? g) Você sugeriu/ divulgou a página para seus amigos do Facebook? Contribuiu para a repercussão da página? h) Considera a página AMBIÉTICA um meio de publicação favorável para expor seu ponto de vista para as pessoas?

2. Sobre o Festival de Vídeo Curta Metragem Ambiental, responda: a) Este contribui para aprendizagem na ética ambiental? b) Este contribui para a divulgação da página $\mathrm{AMBI}-$ ÉTICA?

3. Qual foi sua percepção ao presenciar/participar do Festival de vídeo curta metragem pela página $\mathrm{AMBI}$ ÉTICA?

\section{Questionário B:}

1. Após conhecer a página AMBIÉTICA no Facebook, responda, fundamentado (a) em sua experiência: a) Você desenvolveu maior criticidade ou criatividade sobre determinado tema? b) Mudou algo no seu modo de agir e/ou pensar sobre o meio ambiente? c) Você sugeriu/ divulgou a página para seus amigos do facebook? Contribuiu para a repercussão da página? d) Considera a página AMBIÉTICA um meio de publicação favorável para expor seu ponto de vista para as pessoas?

2. Sobre o Festival de Vídeo Curta Metragem Ambiental, responda com sua opinião: a) Este contribui para maior aprendizagem e criticidade sobre temas relevantes? b) Este desperta a criatividade dos estu- 
dantes durante seu desenvolvimento? c) Esta atividade é considerada importante para o desenvolvimento do estudante? d) Este contribui para a divulgação da página $\mathrm{AMBI}$ ÉTICA? e) Considera o Festival de Vídeo Curta Metragem Ambiental um meio de publicação favorável para expor seu ponto de vista para as pessoas? f) Você considera que esse Festival tenha contribuído para a construção de um conhecimento significativo?

3. Qual foi sua percepção geral ao presenciar/participar do Festival de Vídeo Curta Metragem pela página AMBIÉTICA?

O questionário A foi aplicado para as seguintes turmas: $-5^{\circ}$. semestre de Gestão Ambiental/G.A. (matutino/noturno); - $6^{\circ}$. semestre de Gestão Ambiental (noturno) e $-8^{\circ}$. semestre Ensino Médio Integrado em Química (vespertino); ${ }^{1}$ em 2016; sendo essas turmas administradoras da AMBIÉTICA no semestre; a seguir, a quantidade de estudantes que responderam ao questionário tipo $\mathrm{A}$.

O questionário B foi aplicado para estudantes de diversas turmas do IFMT, que estiveram presentes no encerramento do CURTABLV em março/2016. Ao total, foram 34 questionários respondidos.

\section{Resultados E discuSSÃo}

Cada conteúdo compartilhado na AMBIÉTICA, pelos administradores, desde sua fundação, foi analisado de acordo com os principais conceitos dos autores estudados pensar complexo, autonomia e pensamento narracional - sendo que, cada vez que um desses conceitos é identificado nas postagens, é somado um ponto para o correspondente, assim como mostra a tabela a seguir. Além disso, o número de curtidas, comentários e compartilhamentos, em cada postagem, foi quantificado conforme o assunto abordado.

Entre os conceitos ambientais mais curtidos, comentados e compartilhados na página AMBIÉTICA se tem: reciclagem/ reutilização/ alternativas sustentáveis; conservação da natureza e poluição, respectivamente. Todos esses são diretamente relacionados com a sustentabilidade, considerada a saída para a problemática ambiental do século XXI e, sistematicamente, citados pelos meios de comunicação, atualmente, incluindo também a massiva divulgação nas redes sociais. A justificativa para a enfática preocupação com a sustentabilidade se refere ao fato de que $o$ uso dos recursos naturais é imprescindível ao desenvolvimento econômico, social, cultural, político, científico e tecnológico da humanidade, pois a partir do consumo, do beneficiamento e da industrialização destes, a população humana pôde evoluir, exponencialmente,

Tabela 1. Universo de aplicação do questionário A.

\begin{tabular}{|c|c|c|}
\hline Turma & $\begin{array}{c}\text { Quantidade de } \\
\text { Estudantes }\end{array}$ & $\begin{array}{c}\text { Quantidade de Questionários } \\
\text { Respondidos }\end{array}$ \\
\hline $5^{\circ}$. semestre G.A. (mat.) & 6 & 2 \\
\hline $5^{\circ}$. semestre G.A. (not.) & 25 & 17 \\
\hline $6^{\circ}$. semestre G.A. (not.) & 15 & 11 \\
\hline $8^{\circ}$. semestre Química (vesp.) & 10 & 38 \\
\hline TOTAL & 56 & \\
\hline
\end{tabular}

Fonte: Elaborado pelos autores, a partir de dados da pesquisa.

Essa turma foi a única do Ensino Médio que administrou a página e o fez somente no referido semestre. 
Tabela 2. Análise dos temas da página AMBIÉTICA.

\begin{tabular}{|c|c|c|c|c|c|c|}
\hline Assunto & $\frac{n}{\frac{n}{0}}$ & 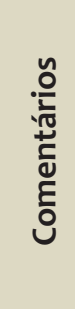 & 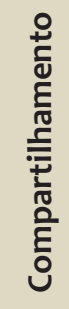 & 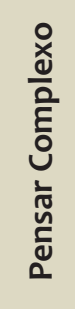 & $\begin{array}{l}\frac{\pi}{E} \\
\frac{0}{0} \\
\frac{0}{0} \\
\frac{7}{3}\end{array}$ & 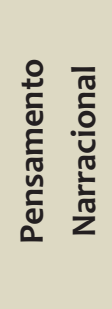 \\
\hline Desmatamento & 684 & 49 & 23 & 112 & 31 & 39 \\
\hline Poluição & 834 & 47 & 41 & 133 & 52 & 44 \\
\hline Conservação da Natureza & 973 & 28 & 37 & 136 & 48 & 54 \\
\hline Consumismo & 305 & 14 & 12 & 53 & 21 & 31 \\
\hline $\begin{array}{c}\text { Reciclagem/ Reutilização/Alternativas } \\
\text { Sustentáveis }\end{array}$ & 1039 & 65 & 56 & 184 & 165 & 80 \\
\hline Saúde/ Epidemias & 178 & 5 & 12 & 28 & 30 & 27 \\
\hline $\begin{array}{c}\text { Aquecimento Global e Desastres } \\
\text { Ambientais }\end{array}$ & 492 & 24 & 34 & 71 & 30 & 35 \\
\hline Ética/ Ética Ambiental & 1127 & 44 & 45 & 185 & 59 & 111 \\
\hline Produções próprias dos estudantes & 343 & 17 & 6 & 31 & 18 & 25 \\
\hline Extinção/ Tráfico/ Maltrato de animais & 227 & 26 & 6 & 37 & 16 & 22 \\
\hline Infraestrutura da Cidade & 80 & 5 & 0 & 25 & 10 & 5 \\
\hline Conflitos Sociais & 63 & 14 & 5 & 8 & 4 & 5 \\
\hline Fome mundial & 37 & 4 & 3 & 6 & 1 & 5 \\
\hline Política & 94 & 10 & 5 & 22 & 10 & 10 \\
\hline Divulgação de Eventos/ Páginas & 382 & 13 & 14 & 29 & 24 & 15 \\
\hline Agrotóxicos/Transgênicos & 97 & 8 & 6 & 12 & 11 & 5 \\
\hline Questões Indígenas & 59 & 11 & 2 & 10 & 8 & 5 \\
\hline Informações Explicativas & 267 & 9 & 4 & 27 & 17 & 22 \\
\hline Violência & 17 & 0 & 0 & 2 & 1 & 0 \\
\hline Filosofia/ Filósofos & 780 & 19 & 21 & 111 & 29 & 102 \\
\hline Festival Curta Metragem & 5852 & 773 & 451 & 36 & 35 & 33 \\
\hline
\end{tabular}

Fonte: Elaborado pelos autores, a partir de dados da pesquisa.

em número de habitantes, em expectativa e qualidade de vida (SOUZA, 2014). Logo, a conciliação da busca de melhores condições materiais de subsistência com a necessidade de um desenvolvimento, que seja sustentável, surge como uma solução prática e acessível para problemas ambientais vivenciados diariamente (BURSZTYN, 2001).

$\mathrm{O}$ assunto com maior repercussão cor- responde ao CURTABLV que, mesmo com suas poucas edições, tem o maior número de "curtidas", comentários e compartilhamentos. Já na análise correspondente aos conceitos se destacam os assuntos: ética/ ética ambiental em pensar complexo, reciclagem/ reutilização/ alternativas sustentáveis em autonomia e filosofia/ filósofos em pensamento narracional. 
As análises ocorreram até o dia 6 de abril de 2016, em que o total de curtidas da AMBIÉTICA somou 3.386 curtidas. Ao analisar o Gráfico 1, pode-se perceber que o número de 'curtidores' cresceu, significativamente, na AMBIÉTICA durante o período de realização dos festivais. Por exemplo, a segunda edição realizada em novembro de 2014 (com 13 vídeos inscritos) e a terceira realizada em março de 2016 (com seis vídeos inscritos). O primeiro Festival foi em março/abril de 2013 (oito vídeos), no entanto, o Facebook não disponibiliza os dados deste período.

Gráfico 1. Total de curtidas na página AMBIÉTICA

Total de curtidas na Página até hoje: 3.386

Total de curtidas na Página

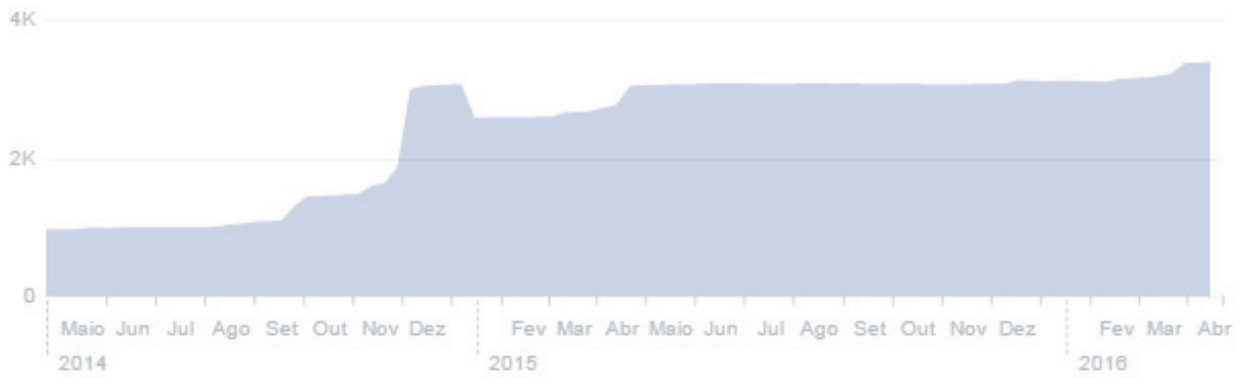

Fonte: Elaborado pelos autores, a partir de dados da pesquisa.

A Tabela 2 ilustra os principais países, cidades e idiomas dos "curtidores" da página AMBIÉTICA no mundo todo. Os dados obtidos comprovam o grande alcance e a intensa contribuição da página, não só no âmbito escolar, mas também em escala mundial.

Tabela 3. Localização das curtidas na página AMBIÉTICA.

\begin{tabular}{|c|c|c|c|c|c|}
\hline Pais & Seus fäs & Cidade & Seus fãs & Idioma & Seus fäs \\
\hline Brasil & 3.294 & Cuiabá, MT & 1.573 & Português (Brasil) & 3.240 \\
\hline México & 10 & Várzea Grande, Mato G.. & 379 & Inglês (EUA) & 46 \\
\hline Portugal & 8 & São Paulo, SP & 49 & Português (Portugal) & 26 \\
\hline Estados Unidos da Am... & 7 & Goiânia, GO & 38 & Espanhol & 23 \\
\hline Espanha & 7 & Rio de Janeiro, RJ & 38 & Espanhol (Espanha) & 17 \\
\hline Japão & 6 & Campo Grande (Mato ... & 34 & Francês (França) & 6 \\
\hline Indonésia & 4 & Cuiabazinho, Mato Gro... & 27 & Árabe & 6 \\
\hline Tailândia & 4 & Curitiba, PR & 27 & Indonésio & 4 \\
\hline Peru & 3 & Manaus, AM & 21 & Tailandês & 4 \\
\hline Venezuela & 3 & Rondonópolis, MT & 20 & Inglês (Reino Unido) & 4 \\
\hline
\end{tabular}

Fonte: Elaborado pelos autores, a partir de dados da pesquisa. 
Sobre o impacto da página AMBIÉTICA, em relação ao ensino e aprendizagem, pode-se observar o resultado da aplicação do questionário anônimo. O Gráfico 2 apresenta as questões que aparecem na ordem do próprio questionário, conforme as palavras-chave de cada questão.

Gráfico 2. Questionário A - Aplicado aos administradores da AMBIÉTICA.

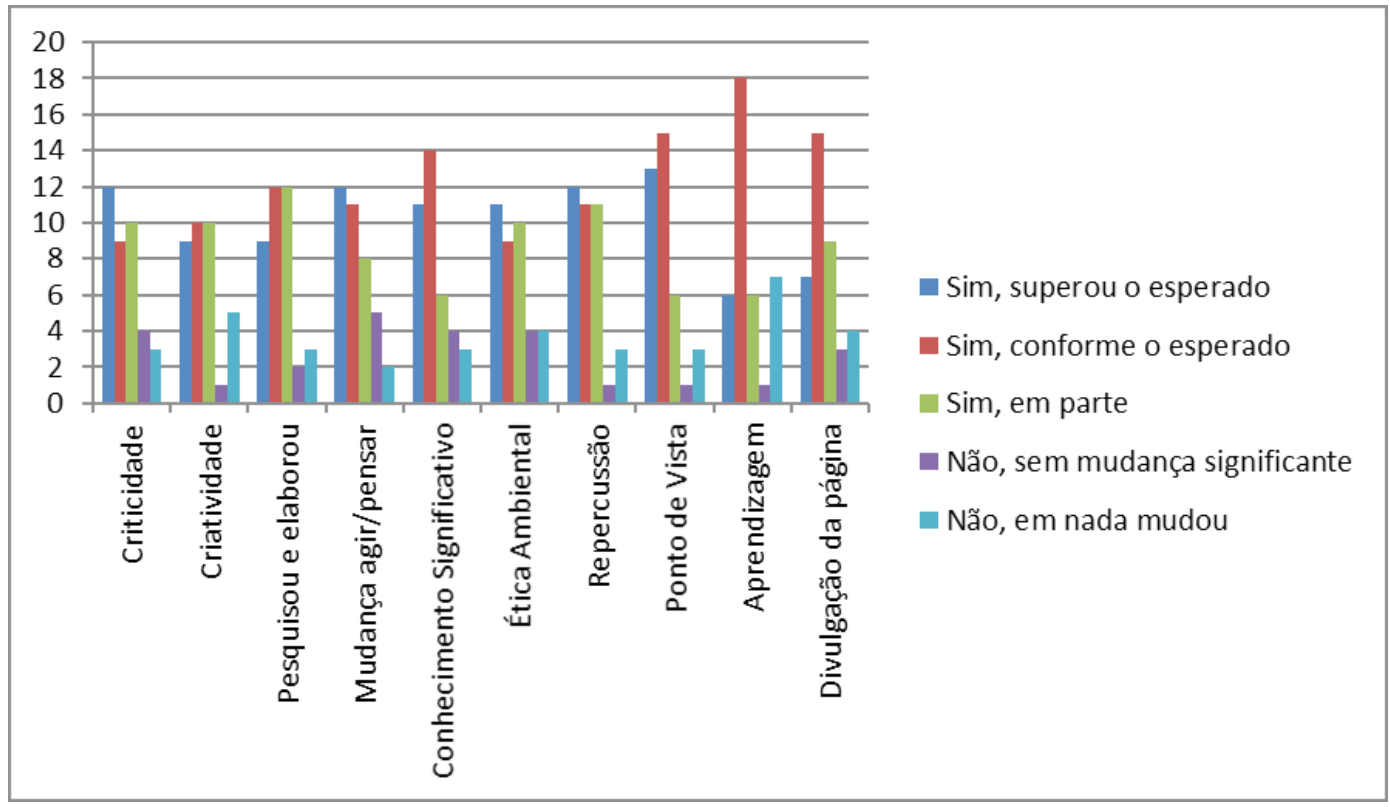

Fonte: Elaborado pelos autores, a partir de dados da pesquisa.

O Gráfico 2 contém a soma da frequência das respostas das quatro turmas para uma possível análise geral. Os resultados "positivos" são destaque em todas as questões, o que mostra que as atividades atingiram os objetivos, segundo as avaliações dos estudantes administradores da AMBIÉTICA, exceto a qual tem por palavra-chave "aprendizagem", que se refere à influência do CURTABLV na aprendizagem de Ética Ambiental. A alternativa "nada mudou", nessa questão, superou as alternativas "conforme o esperado" e "em parte", individualmente.

Há uma significante distinção entre os resultados finais e os resultados de cada turma, o que pode ser influenciado pela idade, grau de escolaridade, grau de envolvimento nas atividades e número de estudantes por turmas, entre outros aspectos. É interessante observar que o número maior de respostas "superou o esperado" e se encontra na turma do Ensino Médio, que pode estar mais habituada ou inserida nas redes sociais e considerá-las importantes ou fundamentais. Ao analisar as respostas do $8^{\circ}$. semestre do Ensino Médio Integrado em Química, pode-se perceber que, na maioria dos critérios estabelecidos, a influência da AMBIÉTICA e também do CURTABLV, de acordo com a opinião dos estudantes da referida turma, supera o esperado. A alternativa "nada mudou" foi respondida apenas duas vezes, uma em cada questão, as quais se referem à influência do CURTABLV na aprendizagem em ética ambiental e sua respectiva contribuição para a divulgação da AMBIÉTICA. Já na turma do $5^{\circ}$. semestre G.A. (matutino), pode-se perceber que todas as alternativas respondidas consideram que os resultados foram positivos, sendo "conforme o esperado" e "em parte" as mais frequentes.

2 Positivo, entre outras expressões, estão entre aspas, pois se referem à afirmação (sim) contida no questionário; o positivo não se refere a um juízo de valor sobre a pesquisa. 
No $6^{\circ}$. Semestre G.A. (noturno), mais uma vez, as alternativas mais frequentes são "conforme o esperado" e "em parte".

Ao analisar os resultados do questionário, as turmas em separado, percebe-se diferenças entre elas. Nos questionários aplicados ao $5^{\circ}$. semestre G.A. (noturno), observa-se uma maior divergência de opiniões, em que as alternativas negativas aparecem com mais frequência em relação às outras turmas. As alternativas mais frequentes correspondem a "conforme o esperado" e "em parte". O resultado "superou o esperado" foi mais significativo somente no item "Mudança agir/pensar", de acordo com a opinião dos estudantes dessa turma. As respostas para a última questão (aberta), nessa turma, também foram as mais críticas, em que quatro estudantes consideraram: "não significou nada para mim", "foge da disciplina”, "sem organização", "um vídeo igual a outro”, "apenas observei os vídeos”, "sem instrução”, "melhor assistir aula de filosofia". Essa atitude crítica pode mostrar que o resultado de favorecer a autonomia foi alcançado, pois emitiram opiniões próprias sobre o mesmo ou, por sua vez, pode até ser que esses estudantes não tenham participado ativamente da produção do vídeo. O que pode ser considerado mais contraditório ou até satisfatório em relação a essa turma é o fato de ter realizado uma das produções audiovisuais vencedoras do CURTABLV 2016, produção que, inclusive, venceu a etapa estadual de o Concurso Pesquisar e Conhecer para Combater o Aedes aegyptietapa estadual, Ministério da Educação (BRASIL, 2016), na categoria Ensino Superior, o que deu visibilidade nacional ao trabalho pedagógico desenvolvido.

As questões aplicadas no dia do encerramento do CURTABLV, em março de 2016, aos participantes do evento (estudantes no geral, não necessariamente administradores ou produtores de vídeos), são apresentadas nos Gráficos 3 e 4, uma vez que o questionário é dividido em duas partes: - questões sobre a AMBIÉTICA; - questões sobre o CURTABLV.

Gráfico 3. Questionário B - Questões sobre a página AMBIÉTICA.

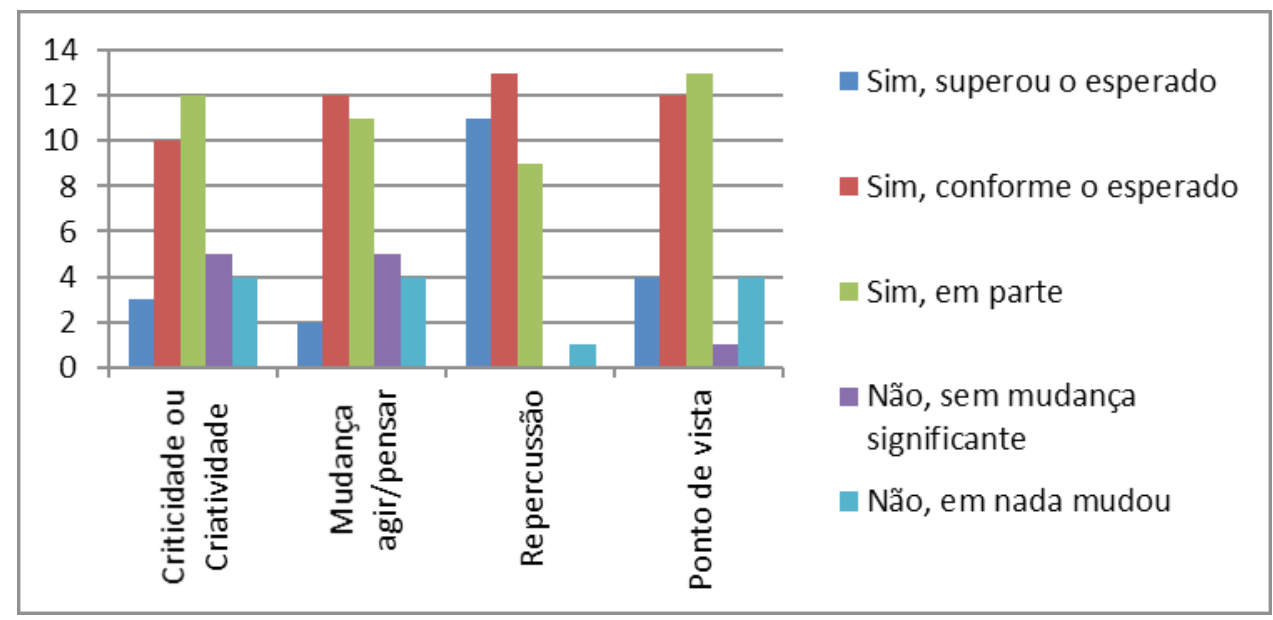

Fonte: Elaborado pelos autores, a partir de dados da pesquisa.

O Gráfico 3 apresenta as questões relacionadas com a página AMBIÉTICA. A percepção geral é de que as alternativas em destaque são as respostas: "conforme o esperado" e "em parte". A questão com a palavra-chave "repercussão" teve frequência maior de respostas "positivas" e esta se refere à autoavaliação de cada estudante, enquanto divulgador da AMBIÉTICA e seus conteúdos. 
Gráfico 4. Questionário B - Questões sobre o CURTABLV.

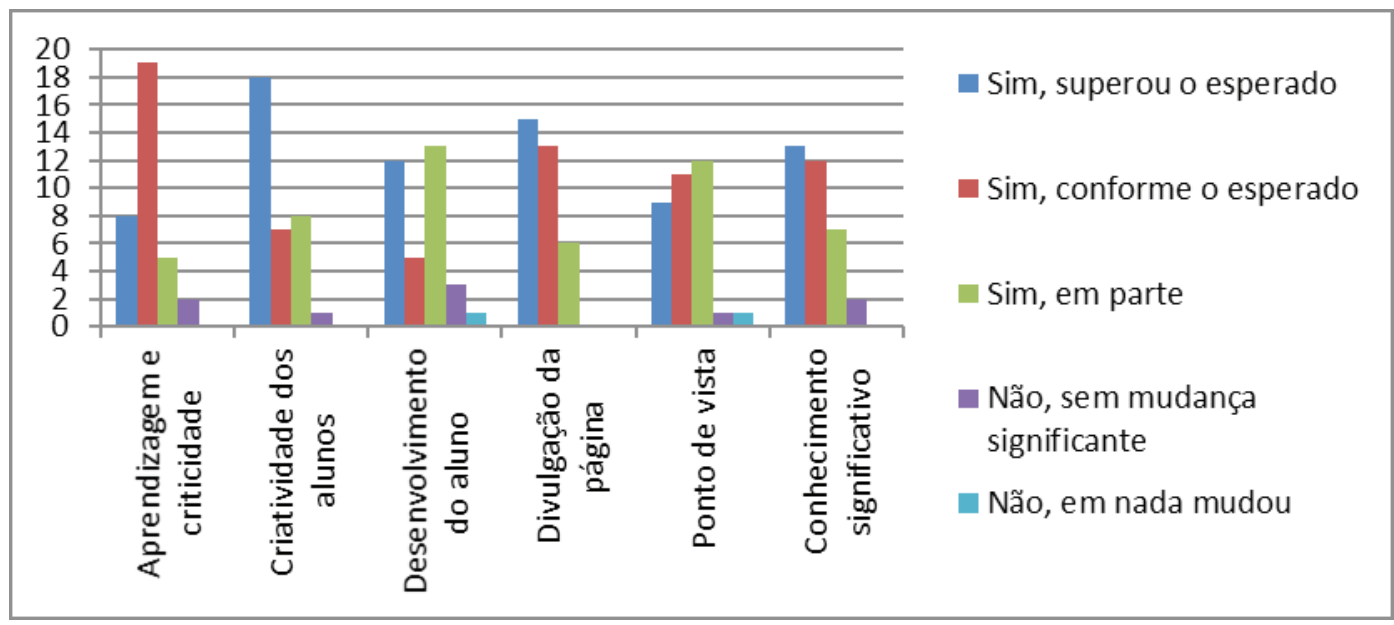

Fonte: Elaborado pelos autores, a partir de dados da pesquisa.

O Gráfico 4 destaca as questões relacionadas ao CURTABLV, as alternativas em destaque são, predominantemente, de resultados positivos em todas as questões, o que constata a eficácia do CURTABLV, em termos de desenvolvimento do estudante e do ser humano.

Pode-se perceber que, no questionário A, respondido por administradores da página AMBIÉTICA, a mesma é avaliada de maneira mais "positiva" e recebe maior reconhecimento em termos de influência, de formação de opiniões críticas construtivas etc. Já no questionário $B$, respondido por estudantes que, não necessariamente tiveram experiência anterior na administração da AMBIÉTICA, a página recebe um percentual menor de aproveitamento, ou seja, o conhecimento da página, dos processos de funcionamento e de construção de conteúdo, auxilia na compreensão de todo o processo, tornando possível um melhor aproveitamento da experiência e do espaço voltado para a disseminação do conhecimento. O contrário também é perceptível na análise, uma vez que os estudantes que participaram do CURTABLV julgam-no "mais positivamente" que os estudantes que administraram a AMBIÉTICA e não participaram somente do CURTABLV.

O envolvimento com as respectivas atividades favoreceu os resultados, esse fato pode significar uma ausência de afastamento para uma visão mais crítica ou, simplesmente, que a experiência com o processo de conhecimento o torna mais significativo e amplo, possibilitando um julgamento com maior propriedade. De uma forma ou de outra, percebe-se que, ao participar das atividades, os estudantes as receberam e avaliaram "positivamente" nos elementos que foram propostos, em relação a uma educação que envolva ensino-pesquisa e extensão, uso de NTICs e aprendizagem significativa.

De um modo geral, as atividades permitiram o desenvolvimento do pensar complexo, da autonomia e do pensamento narracional, em que houve um comprometimento com as atividades e as mesmas ocorreram conforme o esperado.

Sobre as respostas para a última pergunta do questionário (Qual foi sua percepção geral ao presenciar/participar do Festival de Vídeo Curta Metragem pela página AMBIÉTICA?), de um modo geral, as avaliações tanto da AMBIÉTICA quanto do CURTABLV foram satisfatórias, tendo em vista que os estudantes consideram que o CURTABLV favorece a AMBIÉTICA e vice-e-versa, sendo enriquecedora a participação no CURTABLV: 
Acredito que o AMBIÉTICA nasceu pela necessidade de conscientizar a sociedade de modo dinâmico e eficiente sobre os problemas ambientais ao nosso redor, o formato "competitivo" do Festival unido ao objetivo nobre faz com que os participantes sintam um enorme prazer em fazer parte disto (comentário de um questionário).

Alguns disseram sobre o CURTABLV: tornou a "preocupação com o tema mais abrangente"; "contribuiu para o desenvolvimento da página"; "contribuiu para a vida acadêmica”; "uma experiência única, superando o esperado", "me deu um novo ponto de vista em relação aos temas", "boa oportunidade para divulgar as ideias pessoais" a um grande número de pessoas (três respostas); "fortalece a dinâmica em grupo" e "interage as classes" (oito respostas). Muitos afirmaram ser uma experiência: interessante / nova / produtiva / positiva / muito boa / legal / enriquecedora / maravilhosa (16 respostas), ou que favoreceu o conhecimento/aprendizagem/pensamento crítico/criatividade (12 respostas), referindo-se ao CURTABLV e à AMBIÉTICA, destacando sobre a AMBIÉTICA que esta "ajuda na obtenção de conhecimento por meio de artigos confiáveis".

Entre as sugestões: "estudos legislativos"; "mais tempo e recurso tecnológico"; "falta investimento do instituto"; "poderia ser melhor com a participação em massa dos estudantes do campus"; "fiscalização maior da comissão técnica quanto à concorrência desleal (perfis 'fakes')" (duas respostas); "tratar o próximo da melhor forma possível".

Em 2013, quando a tecnologia era (ainda) pouco difundida, a proposta de estudantes de 14 anos de idade produzirem filmes foi inusitada e desafiadora. A tecnologia e a facilidade de acesso ajudaram os participantes a entregar, ano após ano, trabalhos ricos em pensamento complexo, autonomia e criatividade e, inclusive, com qualidade de produção. Smartphones atuais têm recursos inimaginá- veis em câmeras profissionais de alguns anos atrás. Em 2013, estudantes do $2^{\circ}$. semestre de Química gravaram uma adaptação da crônica: $O$ amor tem razões que a razão desconhece (Max Shulman), com uma câmera popular, sem muito cuidado com técnicas profissionais e uma edição básica, e eles conseguiram capturar a essência da história e transmitir a mensagem, o que é almejado por muitos profissionais.

No CURTABLV 2014, estudantes do $6^{\circ}$. semestre gravaram com um celular e alguns cartazes uma mensagem de reflexão sobre as consequências da copa do mundo em Cuiabá, ideia e execução muito simples, mas harmonizada com a trilha sonora perfeita (Hino Nacional). Também, em 2014, os estudantes do $1^{\circ}$. semestre de Química falaram a respeito de humanidade com lições de amizade e de amor, a qualidade do vídeo não deixou a desejar em ponto algum, mesmo tendo sido gravado com um celular e editado em um programa amador, o vídeo se equipara às grandes produções devido ao uso correto dos recursos disponíveis, filtros inteligentes e a trilha sonora perfeita trouxeram qualidade profissional para a criação.

Dois detalhes técnicos foram determinantes para o aprimoramento dos vídeos: a acessibilidade e o acesso à informação. $O$ primeiro, a acessibilidade, diz respeito aos celulares e seus recursos: - de redução de ruído, o que faz o vídeo ficar estável e dá aspecto de filmagem profissional; - controle de ISO (define a sensibilidade do suporte fotográfico); e a resolução cada vez mais precisa. Quanto ao acesso à informação, foi disponibilizado a cada dia um número maior de tutoriais de edição de vídeo e editores gratuitos. A esses elementos se associam aspectos técnicos, a criatividade e a vontade de fazer, o que resulta em produções audiovisuais de excelência. As ferramentas das NTICs permitem o uso autônomo no contexto da produção, a disponibilidade de acesso e a qualidade dos equipamentos possibilitam aos estudantes fazerem escolhas sobre a temática e como desenvolvê-la. Acresce a isto que o trabalho é desen- 
volvido em grupos, nos quais cada um contribui de uma forma, e os que não têm acesso à tecnologia se beneficiam com outros colegas, desenvolvendo assim aspectos sociais fundamentais de um pensar cuidadoso, próprio do pensar complexo.

\section{ConsideraÇões Finais}

Os resultados em relação ao ensino e à aprendizagem, por meio do uso das redes sociais, com a página AMBIÉTICA, evocam uma perspectiva de construção de uma cidadania planetária, corroborando com os conceitos levantados no presente texto de uma educação profissional e tecnológica, que alie os conhecimentos técnicos e a formação humanística de modo interdisciplinar e transversal.

Nessa senda, a página AMBIÉTICA surge como uma alternativa de resposta para essa necessidade, vislumbrando a possibilidade de relacionamento entre diferentes disciplinas e áreas temáticas, além de se apresentar como um espaço democrático e informal, extrapolando os limites físicos das salas de aula, e possibilitando maior interação entre a comunidade acadêmica e temas que afetam o cotidiano da humanidade.

A educação, na era atual, pressupõe um reconhecimento da dinâmica contextual, da globalização e das necessidades planetárias. O'Sullivan, em seu livro: Aprendizagem transformadora - uma visão educacional para o século XXI, mostra a perspectiva de uma educação que evoca três elementos básicos: sobreviver, criticar e criar. Segundo o autor, vive-se hoje na transição da era cenozoico-terminal para o período ecozoico, em que o homem determinaria a sobrevivência ou não do planeta e a educação deveria caminhar para uma consciência planetária, ou seja, envolveria uma educação integral, para a qualidade de vida, em uma visão ecozoica transformadora. O autor admite, inclusive, que para isso haveria uma educação do espírito humano, a partir da diversidade e da percepção da "profunda dimensão da subjetividade no contexto da interioridade, da autopoiesis, da paisagem interior" (O'SULLIVAN, 2004, p. 377). Este autor já citado admite haver uma identificação entre uma "dimensão profunda da espiritualidade" com o "princípio da subjetividade", o que remete novamente a uma compreensão mais ampla de racionalidade, em suas diversas dimensões.

O autor também discute o processo de virtualização e como este faz o homem criar um mundo a partir da riqueza do mundo natural, mas este mundo criado pode ainda apenas reproduzir os sistemas de poder que se observam no natural/cultural. Nesse ponto, o autor mostra que o virtual pode expandir a racionalidade a um convite para o espiritual, mas é apenas uma expansão da mente, a vivência do espiritual permitiria uma experiência mais ampla do corporal até um sentido mais amplo da vida (O'SULLIVAN, 2004).

Observa-se em meio a crenças e a necessidade de ser, em meio a máquinas e a necessidade de conviver, em um contexto de globalização, a necessidade de sobreviver, portanto, as palavras de Castells, em seu livro Sociedade em Rede, ao dizer o que pretende no mesmo, atestam uma possibilidade de uma visão equilibrada para o prosseguimento dos dias globais:

O projeto inspirado deste livro nada contra as correntes de destruição e contesta várias formas de niilismo intelectual, ceticismo social e descrença política. Acredito na racionalidade e na possibilidade de recorrer à razão sem idolatrar a deusa. Acredito nas oportunidades de ação social significativa e de política transformadora, sem necessariamente derivar para as corredeiras fatais de utopias absolutas. Acredito no poder libertador da identidade sem aceitar a necessidade de sua individualização ou de sua captura pelo fundamentalismo (CASTELLS, 2013, p. 24).

Pretende-se com as redes sociais, e a linguagem audiovisual na educação, abrir 
perspectivas de ampliação do conhecimento, em suas dimensões epistemológicas, éticas e políticas, estéticas e sustentáveis, que contemplem uma cidadania planetária e um ambiente natural/cultural/virtual, que favo- reça a beleza das relações inclusivas entre indivíduos livres em uma aldeia global, na qual a formação de profissionais do século XXI seja uma formação completa.

\section{REFERÊNCIAS}

AFONSO, A. M. M.; GONZALEZ, W. R. C. Educação Profissional e Tecnológica: análises e perspectivas da LDB/1996 à CONAE 2014. Ensaio: aval. pol. públ. Educ., Rio de Janeiro, v. 24, n. 92, p. 719-742, jul./set. 2016.

ARENDT, H. A. Condição Humana, 10. ed. Rio de Janeiro: Forense Universitária, 2001.

. A Vida do Espírito. Rio de Janeiro: Relume-Dumará, 1995.

BIGNOTTO, N.; MORAES, E. J. (org.). Hannah Arendt: diálogos, reflexes, memórias. Belo Horizonte: Ed. UFMG, 2003.

BRASIL. Ministério da Educação. Concurso Pesquisar e Conhecer para Combater o Aedes aegypti - etapa estadual, Ministério da Educação, 2016. Disponível em: http://portal.mec.gov.br/ component/tags/tag/37671.. Acesso em: 28 nov. 2018.

BRASIL. Política Nacional dos Resíduos Sólidos. Lei n. 12.305 de 2 de agosto de 2010. Disponível em: http://www.planalto.gov.br/ccivil_03/_at02007-2010/2010/lei//12305.htm.

. Lei 11.892 de 29 de dezembro de 2008. Institui a Rede Federal de Educação Profissional, Científica e Tecnológica, cria os Institutos Federais de Educação, Ciência e Tecnologia, e dá outras providências. Disponível em: http://portal.mec.gov.br/arquivos/pdf/lei_11892_ifets.pdf. Acesso em: 20 mar. 2017.

BURSZTYN, M. (org.). Ciência, ética e sustentabilidade, 2. ed. São Paulo: Cortez; Brasília, DF: UNESCO, 2001.

CASTELLS, M. A sociedade em Rede. São Paulo: Paz e Terra, 2013.

. A galáxia da Internet: reflexões sobre a internet, os negócios e a sociedade. Rio de Janeiro: Jorge Zahar, 2003.

FERREIRA, G. C. Redes Sociais de Informação: uma história e um estudo de caso. Perspectivas em ciência da informação, v. 16, n. 3, p. 208-231, jul./set. 2011.

FREIRE, P. Pedagogia da autonomia: saberes necessário a pratica educativa, 25. ed. São Paulo: Paz e Terra, 1996.

. Pedagogia do oprimido, 17. ed. Rio de Janeiro: Paz e Terra, 1987.

. Política e educação: ensaios, 5. ed. São Paulo: Cortez, 2001. 
LÉVY, P. As tecnologias da inteligência: o futuro do pensamento na era da informática. Rio de Janeiro: Editora 34, 1995.

. Cibercultura. Rio de Janeiro: Editora 34, $1999 \mathrm{~b}$.

. A Inteligência Coletiva. São Paulo: Loyola, 1998.

. O que é o Virtual? São Paulo: Editora 34, 1999c.

LIPMAN, M. Caring as Thinking. In: Inquiry. New Jersey: Upper Montclair, v. XV, n. 1, p. 1-13, 1995.

LIPMAN, M. O Pensar na Educação. Petrópolis: Vozes, 1995.

MACHADO, J. R.; TIJIBOY, A. V. Redes Sociais Virtuais: em espaço para efetivação da aprendizagem cooperativa. Novas tecnologias na educação, v. 3, n. 1, mai. 2015.

MARCHESSOU, F. Estratégias, Contextos, Instrumentos, Fórmulas: a contribuição da tecnologia educativa ao Ensino Aberto e à Distância. Revista Tecnologia Educacional, v. 25, n. 139, nov.l dez. 1997, p. 6 a 15.

O’SULLIVAN, E. Aprendizagem Transformadora - uma visão educacional para o século XXI. São Paulo: Cortez: Instituto Paulo Freire, 2004.

RECUERO, R. Redes sociais na internet. Porto Alegre: Sulina, 2009.

SHARP, A.; SPLITTER, L. J. Uma nova educação: a comunidade de investigação na sala de aula. São Paulo: Nova Alexandria, 1998.

SIMÕES, I. A. G. A Sociedade em Rede e a Cibercultura: dialogando com o pensamento de Manuel Castells e de Pierre Lévy na era das novas tecnologias de comunicação. Disponível em: http://www.insite.pro.br/2009/Maio/sociedade_ciberespa\%C3\%A70_Isabella.pdf.. Acesso em: 21 mar. 2016.

SOUZA, F. S. C. de. A ocupação de áreas de risco excluídas da delimitação das Áreas de Preservação Permanente pelo Código Florestal: o caso de Santo Antônio de Leverger (MT). Monografia. Cuiabá: Universidade Federal de Mato Grosso, 2014.

STATISTA. Number of monthly active Facebook users worldwide as of 3rd quarter 2018 (in millions). October, 2018a Disponível em: https://www.statista.com/statistics/2648. 10/numberof-monthly-active-facebook-users-worldwide/. Acesso em: 26 nov. 2018.

STATISTA. Ranking mundial de los 10 países con más usuarios de Facebook a fecha de abril de 2018 (en millones), abril, 2018b. Disponível em: https://es.statista.com/estadisticas/518638/ ranking-de-los-paises-con-mas-usuarios-de-facebook-a-nivel-mundial/. Acesso em: 26 nov. 2018.

ZABALA, A. Enfoque Globalizador e Pensamento Complexo: uma proposta para currículo escolar. Porto Alegre: Artmed Editora, 2002. 
ZENÓBIO, J. H.; GROSSI, M. G. R. Redes Sociais na Educação: Benefícios no Uso de Ferramentas do Facebook pelos Professores nos Processos de Ensino e Aprendizagem. Anais... SEMINÁRIO NACIONAL DE EDUCAÇÃO PROFISSIONAL E TECNOLÓGICA Disponível em: http://www.senept. cefetmg.br/galerias/Anais_2014/GT02/GT_02_x22x.pdf.. Acesso em: 12 abr. 2016.

\section{RAQUel MARTINS Fernandes Mota}

Pós-doutoranda em Psicologia Social da Universidade Federal da Paraíba. Professora do Instituto Federal de Educação, Ciência e Tecnologia de Mato Grosso (IFMT), campus Bela Vista. raquel. mota@blv.ifmt.edu.br

\section{Paulo Alves Oliveira}

Bacharel em Comunicação Social com habilitação em Jornalismo, pela Universidade Federal de Mato Grosso (UFMT)Técnico Administrativo do Instituto Federal de Educação, Ciência e Tecnologia de Mato Grosso (IFMT), Campus São Vicente.cos.paulooliveira@gmail.com

\section{DAIARA COLPANI}

Graduada em Engenharia Química pela Universidade Federal do Amazonas (UFAM). Técnica no Instituto Federal de Educação, Ciência e Tecnologia de Mato Grosso (IFMT), campus Bela Vista. daiara.colpani@hotmail.com

\section{RODRIGO RIBEIRO OLIVEIRA}

Doutorado em Engenharia de Produção pela Universidade Metodista de Piracicaba (UNIMEP). Professor do Instituto Federal de Educação, Ciência e Tecnologia de São Paulo (IFSP), campus São Paulo.rodrigoribeirosp@hotmail.com

Submetido em: 30-11-2018

Aceito em: 10-10-2019 